DOI: https://doi.org/10.24867/02IH01Komar

\title{
UPRAVLJANJE PNEUMATSKOM OPRUGOM SAPOVRATNOM SPREGOM PO POZICIJI
}

\section{POSITION FEEDBACK CONTROL OF PNEUMATIC SPRING}

\author{
Nenad Komar, Fakultet tehničkih nauka, Novi Sad
}

\begin{abstract}
Oblast - MEHATRONIKA
Kratak sadržaj - U ovom radu prikazane su opruge kao mašinski elementi, kao i različite vrste upravljanja sa povratnom spregom. Prikazan je postojeći sistem pneumatske opruge. Razvijeno je novo upravljanje sa povratnom spregom po poziciji i implementirano je na postojeći sistem. Testiran je rad sistema. Izvučeni su potrebni zaključci.
\end{abstract}

Ključne reči: Upravljanje po poziciji, Pneumatska opruga, Povratna sprega

Abstract - In this paper the spring as mechanical element is described. The different types of feedback control are shown. The description of current pneumatic spring is shown. The new position feedback control is developed and implemented to the current system. The system is tested. All necessary conclusions are drawn.

Keywords: Position control, Pneumatic springs, Feedback loop

\section{UVOD}

Da bi se moglo uspešno upravljati nekim sistemom potrebno je poznavati prirodu procesa koji se u njemu odvijaju i imati na raspolaganju odgovarajući upravljački algoritam kojim je moguće postići zahtevane ciljeve, tj. performanse sistema. Pored ovoga, neke upravljačke strategije zahtevaju i treći skup informacija koji se odnosi na poznavanje tekućeg stanja upravljanog procesa. Ako se ovo ima u vidu, onda se upravljački sistemi mogu podeliti na sisteme bez povratne sprege i sisteme sa povratnom spregom.

Upravljanje u sistemima sa otvorenom povratnom spregom se zasniva na zadatom algoritmu baziranom na poznavanju funkcionisanja upravljanog sistema i na njega ne utiču promene izlaznih promenljivih ili smetnje. Algoritam takvog funkcionalnog upravljanja se obično definiše pri projektovanju sistema a zatim se realizuje odgovarajući uređaj, tj. programator. Ovaj oblik upravljanja ima široku primenu iako ima ozbiljne nedostatke. Osnovni nedostatak se pokazuje u slučajevima kada sistem promeni režim i uslove rada. Tada može doći do nedozvoljenog odstupanja između željenog i stvarnog ponašanja sistema. Prvi način prevazilaženja ovog problema se može realizovati korekcijom funkcionalnog upravljačkog algoritma na bazi merenja smetnji. Ovaj oblik upravljanja se zove upravljanje po smetnji. Drugi način se realizuje uvođenjem povratne sprege u sistem.

Zadatak povratne sprege je da vraća na ulaz u sistem izmerene izlazne veličine sistema upoređujući ih sa referentnim, željenim vrednostima izlaza. Na taj način se formira greška ili odstupanje nominalnog od stvarnog ponašanja i ona predstavlja veličinu koju upravljački sistem treba da minimizira [1].

NAPOMENA:

Ovaj rad proistekao je iz master rada čiji mentor je bio dr Dragan Šešlija, red.prof.
$\mathrm{U}$ upravljačkom sistemu prikazanom u ovom radu korišćene su dve vrste upravljanja sa povratnom spregom:

- upravljanje po poziciji pri čemu se za cilj ima dostizanje odgovarajuće pozicije klipnjače cilindra dvosmernog dejstva a kao povratna spega korišćena je informacija o trenutnoj poziciji koja se dobija sa digitalne merne letve, $\mathrm{i}$

- upravljanje po sili gde se vrši regulacija zadate sile na klipu cilindra podešavanjem vrednosti pritiska (direkna proprocionalnost između sile i pritiska) a kao povratna sprega korišćena je informacija o trenutnoj vrednosti pritiska koja se dobija sa daljinski upravljanog regulatora pritiska.

Na slici 1 prikazan je sistem sa povratnom spregom po sili i po poziciji.

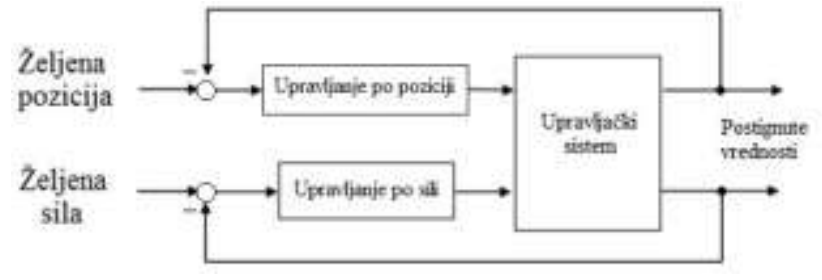

Slika 1. Sistem sa zatvorenom povratnom spregom po sili $i$ po poziciji

\section{OPIS EKSPERIMENTA}

Pneumatska opruga je sistem koji omogućava simulaciju rada mehaničke opruge pri različitim uslovima pri sabijanju. Razvijena je na Fakultetu tehničkih nauka u Novom Sadu. Predstavlja klasični mehatronički sistem jer u sebi integriše više različitih elemenata. Korisnik u korisničkoj aplikaciji unosi parametre opruge na osnovu kojih se proračunava željena vrednost pritiska u uparvljačkom sistemu. Zatim se podaci preko serijske komunikacije šalju na programabilno logički kontroler (u daljem tekstu PLK). PLK, nakon prijema odgovarajuće informacije, istu prosleđuje do regulatora pritiska pomoću koga se pritisak u odgovarajućem delu sistema postavlja na proračunatu vrednost. Nakon toga, PLK pokreće sistem. Jedan cilindar dvosmernog dejstva se koristi za simulaciju rada opruge na taj način što mu se u radnom hodu, preko regulatora pritiska, u klipnu stranu dovodi vazduh pod pritiskom ( $\mathrm{u}$ daljem tekstu VPP) koji je prethodno podešen na željenu vrednost. U klipnjačinoj strani, u početnom trenutku nalazi se VPP od 6 bar koji se dovodi direktno sa kompresora. Kako je vrednost pritiska u klipnoj strani manja od vrednosti pritiska u klipnjačinoj strani, cilindar miruje. Naspram njega postavljen je drugi pneumatski cilindar, identičnih karakteristika koji predstavlja silu koja sabija oprugu. Radom ovog pneumatskog cilindra upravlja PLK preko odgovarajućeg 
komandnog razvodnika 3/2. Klipna strana ovog cilindra napaja se VPP iz kompresora sa vrednošću od 6 bar. U zavisnosti od vrednosti pritiska na izlazu iz regulatora pritiska, izvlačenje klipnjače cilindara koji simulira silu će biti teže ili lakše, odnosno klipnjača cilindra koji simulira oprugu će se uvući više ili manje. Na sve to je još dodata merna letva koja meri koliko se zaista pomerila klipnjača, odnosno proverava koliko se „sabila“ opruga u odnosu na definisane vrednosti i podatke preko Arduina šalje na PCračunar koji se isčitavaju u korisničkoj aplikaciji. Na taj način, zaokružen je jedan radni ciklus opisanog sistema.

\section{HARDVERSKI DEO SISTEMA}

Hardverski deo sistema sastoji se od izvršnih organa, regulatora pritiska, PLK, merne letve i Arduina.

\subsection{Izvršni organi}

U ovom sistemu, izvršni organi su pneumatski cilindri dvosmernog dejstva sa oznakom DNC-32-100-PPV-A, proizvođača FESTO. Ima ih ukupno dva. CAD model [2] izabranog pneumatskog cilindra dvosmernog dejstva prikazan je na slici 2.

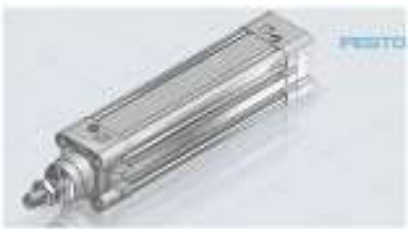

Slika 2.CAD model izabranog pneumatskog cilindra

\subsection{Regulator pritiska}

Kako bi se pritisak u odgovarajućem delu upravljačkog sistema podesio na neku vrednost, neophodno je koristiti regulator pritiska [3]. Regulator koji je zadovoljio postavljene uslove ima oznaku MS6 - LRE- 1/4 -D7 - OP - PI-SK5-VK5-VJBE, i proizvođača je FESTO (Slika $3)$.

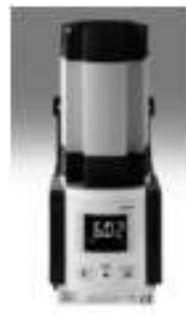

Slika 3. Regulator pritiska

\subsection{PLK FEC 660 Festo}

Prilikom realizacije eksperimenta korišćen je 12 - bitni kontroler FEC660 Standard, proizvođača FESTO, sa sledećim karakteristikama [4]:

$$
\begin{aligned}
& \text { - } 4 \times 8 \text { digitalna ulaza, } \\
& \text { - } 2 \times 8 \text { digitalna izlaza, } \\
& \text { - } 3 \times \text { analogna ulaza, } \\
& \text { - } 1 \times \text { analogni izlaz, } \\
& \text { - } 1 \times \text { eternet (eng. Ethernet) port i } \\
& \text { - } 2 \text { x serijska porta. }
\end{aligned}
$$

Izgled izabranog kontrolera sa odgovarajućim elementima prikazan je na slici 4.

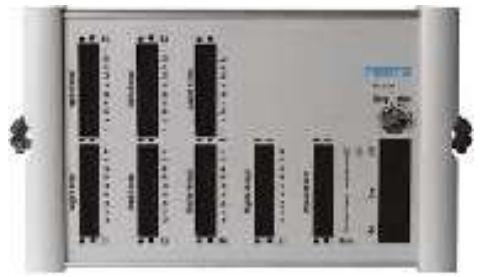

Slika 4. FEC 660 PLK

\subsection{Merna letva JC800}

Kako bi se odredila pozicija klipnjače cilindra koji simulira oprugu, korišćena je merna letva JC800. Izgled merne letve prikazan je na slici 5.

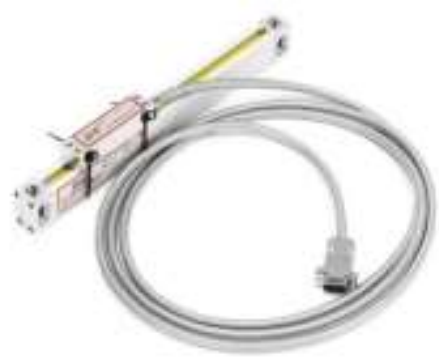

Slika 5. Merna letva JC800

\subsection{Arduino UNO R3}

Arduino Uno [5] je mikrokontrolerska ploča bazirana na Atmega328 mikrokontroleru. Poseduje 14 digitalnih ulaza/izlaza (od kojih 6 mogu služiti kako PWM izlazi), 6 analognih ulaza, $16 \mathrm{MHz}$ kristal oscilator, USB konektor za programiranje i vezu s računarom, konektor za eksterno napajanje (ukoliko se ne napaja sa USB-a), ICSP konektor i taster reset. Na slici 6 prikazan je izgled Arduino UNO R3 mikrokontrolerske ploče.

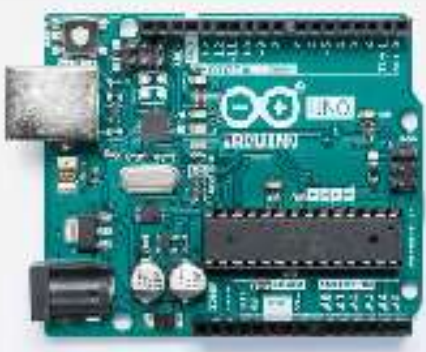

Slika 6. Izgled Arduino UNO R3 ploče

3.6 Povezivanje PC-računara sa PLK-om i Arduinom Za povezivanje PC-računara sa PLK-om korišćen je kabl za povezivanje PS1 SM14 koji se može koristiti za uspostavljanje direktne veze između PLK-a i eksternog računara. Način povezivanja je prikazan na slici 7 .

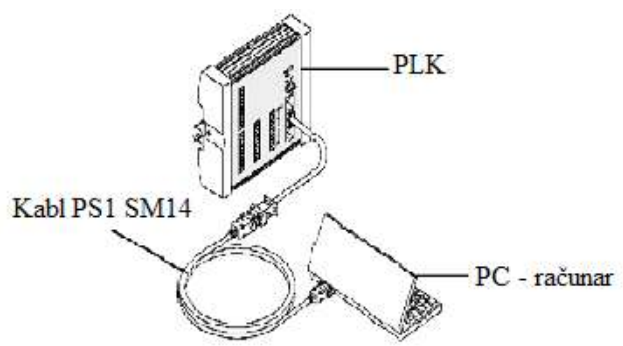

Slika 7. Povezivanje PC-računara sa PLK-om $\mathrm{Za}$ povezivanje $\mathrm{PC}$-računara sa Arduinom korišćen je USB kabl. Način povezivanja PC-računara sa Arduinom prikazan je na slici 8 .

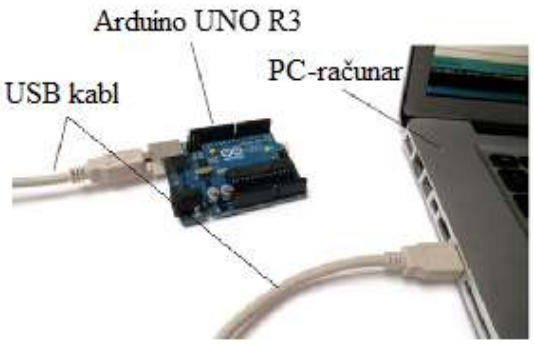

Slika 8. Povezivanje PC-računara sa Arduinom 


\subsection{Način povezivanja merne letve sa Arduinom}

Na slici 9 predstavljen je način povezivanja merne letve sa Arduinom. U konkretnom slučaju, za povezivanje su iskorišćeni muško-ženski kratkospojnici.

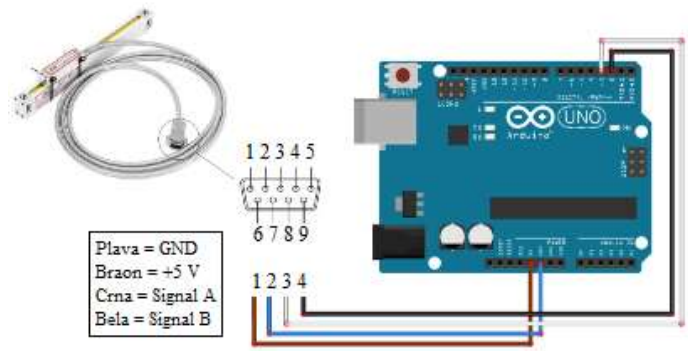

Slika 9. Način povezivanja merne letve sa Arduinom

\subsection{Upravljačka šema}

Upravljačka šema urađena je u programskom okruženju FluidDraw i prikazana je na slici 10. Na levoj strani slike predstavljena je pneumatska šema, a na desnoj strani slike prikazana je elektrošema povezivanja komponenti sa PLK-om.

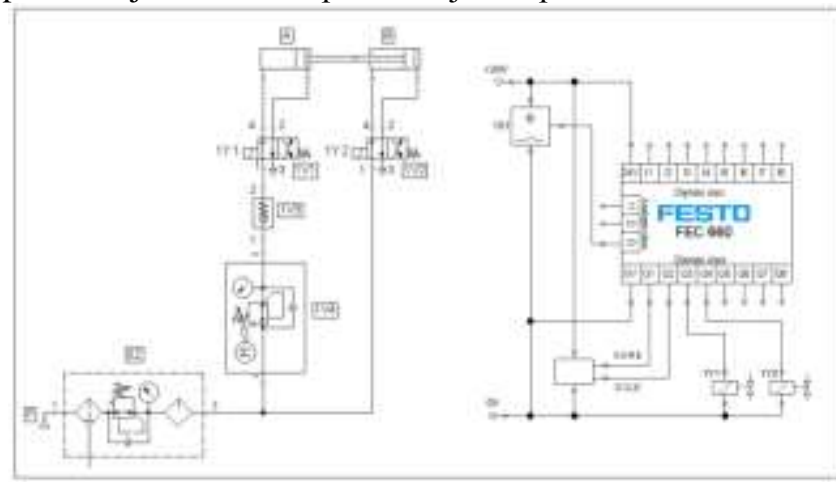

Slika 10. Upravljačka šema

\section{SOFTVERSKI DEO SISTEMA}

Softverski deo se sastoji od korisničke aplikacije, programskog koda za PLK i programskog koda za Arduino.

\subsection{Korisnička aplikacija}

Korisnička aplikacija napisana je u programskom jeziku C\#. Izgled korisničke aplikacije prikazan je na slici 11.

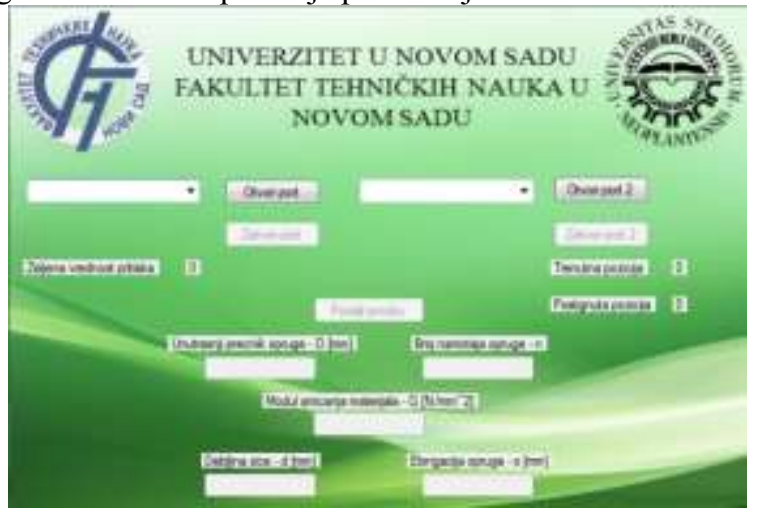

Slika 11. Izgled korisničke aplikacije

Korisnička aplikacija se satoji iz tri dela. Prvi deo je deo za manipulaciju sa portovima, odnosno deo gde se otvaraju i zatvaraju komunikacioni portovi. U padajućim menijima, koji se nalaze pored dugmeta Otvori port i Otvori port 2, potrebno je izabrati odgovarajuće portove. Prilikom izbora portova potrebno je paziti da se u padajućem meniju pored dugmeta Otvori port izabere onaj port na kojem je povezan PLK a u drugom padajućem meniju da se izabere port na koji je povezan Arduino. U suprotnom aplikacija neće raditi zato što se jedan port koristi za slanje podataka a drugi se koristi za prijem podataka.

Drugi deo aplikacije predstavlja deo u kome se može proračunati željena vrednost pritiska, zatim pratiti trenutna pozicija merne letve $i$ iščitati postignuta pozicija merne letve. Treći deo aplikacije koristi se za unos parametara opruge. Potrebno je uneti unutrašnji prečnik opruge, broj namotaja, modul smicanja, debljinu žice i elongaciju opruge. Na osnovu ovih parametara računa se vrednost pritiska koja se šalje PLK kada se pritisne dugme pošalji podatke.

\subsection{Programski kod za PLK}

Programski kod za PLK razvijen je u programskom jeziku FST4.10 (Slika 12) [6]. Kod za PLK sastoji se iz dva dela od kojih je prvi deo programa, deo za serijsku komunikaciju između PLK i računara a drugi deo programa koristi se za upravljanje regulatorom pritiska.

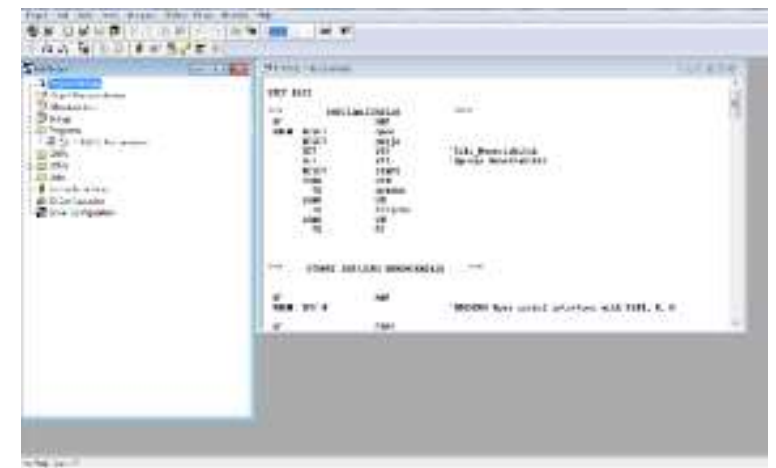

Slika 12. Izgled programskog jezika FST 4.10

\subsection{Programski kod za Arduino}

Programski kod za Arduino razvijen je u programskom okruženju Arduino IDE (Slika 13). Sastoji se iz dva dela od kojih je prvi deo programa deo za serijsku komunikaciju između Arduina i PC-računara a drugi deo programa koristi se za preuzimanje podataka sa merne letve. Programski kod funkcioniše tako što se sa merne letve očitava vrednost njenog pomeraja a zatim se ta vrednost preko serijske komunikacije šalje na PC-računar.

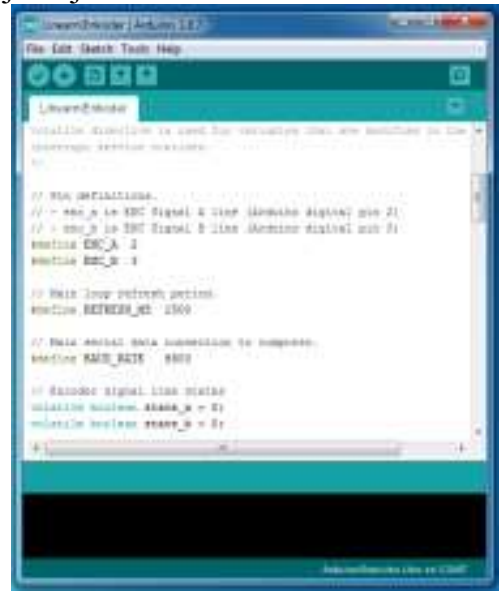

Slika 13. Izgled Arduino IDE razvojnog okruženja

\subsection{Upravljački algoritam}

Radi lakšeg razumevanja, na slici 14 prikazan je izgled dijagrama toka (upravljačkog algoritma) sistema o kome se govori u ovom radu. 


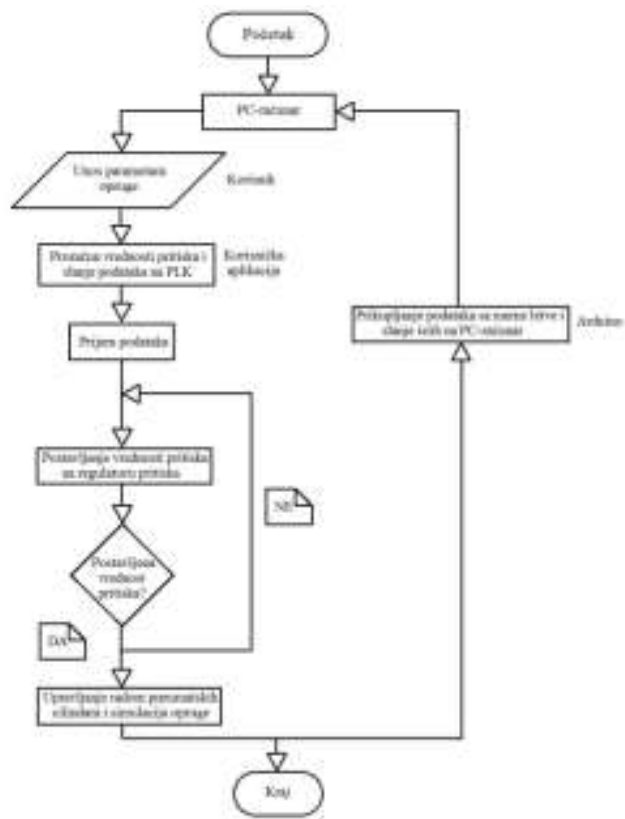

Slika 14. Upravljački algoritam

\section{REZULTATI MERENJA}

U tabeli 1 prikazani su parametri opruge i vrednost pritiska koji se proračunava na osnovu tih parametara.

Tabela 1: Vrednosti parametara opruge i željene vrednosti pritiska

\begin{tabular}{|c|c|c|c|c|c|}
\hline 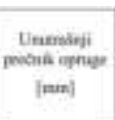 & 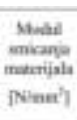 & 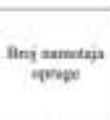 & $\begin{array}{c}\text { Dontjina no } \\
\text { fami }\end{array}$ & $\begin{array}{l}\text { Elinusione } \\
\text { gqueve } \\
\text { Jman| }\end{array}$ & 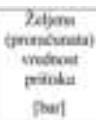 \\
\hline 16,4 & $34 \cdot 10^{\prime}$ & 7 & 3 & 10 & 100 \\
\hline 105 & $36-107$ & 9 & 3 & 25 & 1.56 \\
\hline 145 & $26 \cdot 10^{7}$ & 7 & 3 & iti & 2,44 \\
\hline 14.5 & $36 \mathrm{It}^{7}$ & 7 & 3 & 93 & XQ \\
\hline 125 & $2 t-3 \sigma^{\prime}$ & 7 & 3 & $7 \pi$ & 236 \\
\hline 16,4 & $36 \cdot 10^{7}$ & 7 & 4 & 17 & 5,62 \\
\hline
\end{tabular}

U tabeli 2 prikazane su proračunate i postignute vrednosti pritiska.

Tabela 2: Proračunate i postignute vrednosti pritiska

\begin{tabular}{|c|c|}
\hline 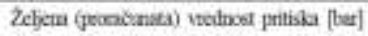 & Postignula vrednosa pritiska [bar] \\
\hline 1.05 & 1 \\
\hline 1.56 & $15 ?$ \\
\hline 2,49 & 2,49 \\
\hline 3,42 & 3,5 \\
\hline 4,36 & 4,58 \\
\hline 5.65 & 5,65 \\
\hline
\end{tabular}

U tabeli 3 prikazane su vrednosti za pomak cilindra koji simulira oprugu.

Tabela 3: Zadate i postignute vrednosti za pomak cilindra

\begin{tabular}{|c|c|}
\hline Zadsa pozicija [nm! & Postignesa pozictia [mm] \\
\hline 10 & 16 \\
\hline 17 & 24 \\
\hline 25 & 31 \\
\hline 20 & 51 \\
\hline 55 & 63 \\
\hline 70 & 82 \\
\hline
\end{tabular}

U tabeli 2 se može videt da su vrednosti pritiska u većini slučajeva približno iste, odnosno za željenu vrednost pritiska od 5 bar postignuta je vrednost od 5,01 bar itd., čime je uspešno realizovano upravljanje po sili. Iz tabele 3 se može videti da postoji odstupanje između zadate i postignute vrednosti, odnosno vrednosti željene i postignute pozicije razlikovale su se u proseku za oko $10 \mathrm{~mm}$, što se može pripisati zanemarivanju uticaja trenja i drugih otpora koji se javljaju u sistemu.

\section{ZAKLJUČAK}

U ovom radu prikazan je jedan od načina realizacije upravljanja pneumatskom oprugom sa povratnom spregom po poziciji. Opisan je celokupan hardverski i softverski deo. U poglavlju koje čini hardverski deo sistema prikazana je mehanička konstrukcija sistema, kao i osnovne komponente potrebne za izvođenje eksperimenta. Predstavljeni su PLK i merna letva koji su korišćeni. Pored toga, opisan je i Arduino koji se koristi za iščitavanje podataka sa merne letve. Pored opisa osnovnih delova, dat je i opis o načinu povezivanja PC-računara sa PLKom i načinu povezivanja PC-računara sa Arduinom. Na kraju ovog poglavlja predstavljena je upravljačka šema sistema i elektrošema povezivanja sa PLK-om. Pored hardverskog dela predstavljen je i softverski deo u kome su opisani programi koji su se koristili za kreiranje korisničke aplikacije, za programiranje PLK i za programiranje Arduina. Na samom kraju, dat je algoritam rada, odnosno objašnjenje kako zapravo celokupan sistem funkcioniše.

Kao što je u samom uvodu rečeno korišćene su dve vrste upravljanja sa povratnom spregom: upravljanje po sili i upravljanje po poziciji. U prvom slučaju cilj je bio da se reguliše zadata sila na klipu cilindra koji simulira oprugu podešavanjem vrednosti pritiska na regulatoru pritiska, a u drugom slučaju cilj je bio dostizanje odgovarajuće pozicije klipnjače cilindra a kao povratna spega korišćena je informacija o trenutnoj pozciji koja se dobija sa merne letve.

Buduća istraživanja na ovom sistemu biće pronalaženje uzroka grešaka kod regulacije po poziciji, kao i otklanjanje istih.

\section{LITERATURA}

[1] M. Stojić, Kontinulani sistemi automatskog upravljanja, Nauka, Beograd, 1996.

[2] S. Tiko, Solid Works za mašinske inženjere, Mikro knjiga, Beograd, 2011.

[3] Tehnička dokumentacija izabranog daljinski upravljanog regulatora pritiska -

http://www.festo.com/cat/de de/data/

doc engb/PDF/EN/MS-REGULATORS_EN.PDF, pristupljeno dana 23.08.2018. godine

[4] Tehnička dokumentacija PLK -

http://www.festo.com/net/SupportPortal/Files/10059/IPC

-FECPSI-US.PDF, pristupljeno dana 03.09.2018. godine

[5] Internet stranica -

https://www.scribd.com/document/362940141/Arduino-

Radionica, pristupljeno dana 06.09.2018. godine

[6] Tehnička dokumentacija programskog jezika FST4.10 -

http://ftp.me.hwh.edu.tw/ftp/PLC/Festo/FST4\%20

Manual.pdf,pristupljeno dana 03.10.2018. godine

\section{Kratka biografija:}

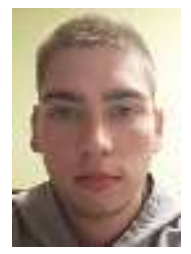

Nenad Komar rođen u Zrenjaninu 1994. god. Osnovne studije završio na Fakultetu tehničkih nauka, smer Mehatronika, 2017 godine.

kontakt:nenadkomar@gmail.com 